\title{
ACROANGIODERMATITIS OF MALI
}

\author{
Lucky Sinha1, Padmavathi², Jyothi Anantharaj ${ }^{3}$
}

1Post Graduate, Department of Pathology, Rajarajeswari Medical College and Hospital.

2 Post Graduate, Department of Pathology, Rajarajeswari Medical College and Hospital.

3Professor, Department of Pathology, Rajarajeswari Medical College and Hospital.

\begin{abstract}
Acroangiodermatitis (Synonym: pseudo-Kaposi sarcoma) is an unusual, benign, self-limited angioproliferative lesion. It is often associated with chronic venous insufficiency, arteriovenous malformation of the legs, chronic renal failure treated with dialysis, paralyzed legs and amputation stumps. This condition presents clinically as purple-colored patches, plaques or nodules on the lower extremities. Despite being benign, this lesion assumes importance because of its close resemblance to the aggressive Kaposi sarcoma and requires histopathological examination for its diagnosis. We describe here a case of a 55 -year old female who presented with raised, hyperpigmented lesions over both ankles and histopathological examination from one of the lesions confirmed the diagnosis of acroangiodermatitis.
\end{abstract}

\section{KEYWORDS}

Acroangiodermatitis, Angioproliferative, Chronic Venous Insufficiency.

HOW TO CITE THIS ARTICLE: Sinha L, Padmavathi, Anantharaj J. Acroangiodermatitis of mali. J. Evolution Med. Dent. Sci. 2016; 5(18):911-913, DOI: $10.14260 /$ jemds/2016/211

\section{INTRODUCTION}

Acroangiodermatitis is a reactive angiodysplasia of cutaneous blood vessels associated with increased venous pressure and stasis or with vascular anomalies, such as Klippel-Trenaunay syndrome.1,2 It has been referred to by various names including 'Angiodermite de Favre et Chaix' in the French literature and as congenital dysplastic angiopathy, pseudoKaposi sarcoma or acral capillary angiomatosis. 3,4 Mali et al. reported 18 such cases in 1965 and adopted the term 'Acroangiodermatitis.' 5 These lesions mimic Kaposi sarcoma and therefore histopathological examination is mandatory for their diagnosis and differentiation.

\section{CASE REPORT}

A 55-year-old lady presented with raised lesions, itching and hyperpigmentation of both lower legs for 7 years. There was a history of recurrent bleed over the ankles. Varicosities were noted in both lower extremities. On examination, lichenified plaques measuring $10 \times 10 \mathrm{cms}$ were seen over the lateral malleoli of both lower limbs [Figure 1]. Surface was dry and depigmented focally with areas of ulceration and healing. Varicose eczema, lichen simplex chronicus and psoriasis were the differential diagnoses considered clinically. A biopsy was done and tissue submitted for histopathology.

Grossly, the specimen was a skin covered tissue bit measuring $4 \times 1.2 \times 0.3 \mathrm{cms}$; surface of skin showed an ulcer measuring $1 \mathrm{~cm}$ in diameter. Ulcer base was indurated. On microscopy, sections from skin showed surface ulceration covered with necrotic debris. Hyperkeratosis and parakeratosis was seen.

Financial or Other, Competing Interest: None.

Submission 18-01-2016, Peer Review 15-02-2016,

Acceptance 19-02-2016, Published 03-03-2016.

Corresponding Author:

Dr. Jyothi Anantharaj,

$255,11^{\text {th }} B$-Cross,

20 $0^{\text {th }}$ Main,

JP Nagar, 2 ${ }^{\text {nd }}$ Phase,

Bangalore-560078.

E-mail: jyoki255@yahoo.co.in

DOI: $10.14260 /$ jemds/2016/211
The epidermis showed acanthosis with anastomosing rete and spongiosis. There was lobular proliferation of dilated, thick walled capillaries in the dermis, lined by plump endothelial cells without atypia or mitotic activity and surrounded by mixed inflammatory infiltrate [Figures 2, 3 and 4]. Lumina could not be identified in some of the capillaries. No slit-like vascular spaces was seen. The intervening stroma was edematous with extravasated RBCs and siderophages [Figures 2 and 4]. Based on the history clinical and microscopic findings, a final diagnosis of Acroangiodermatitis of Mali was made.

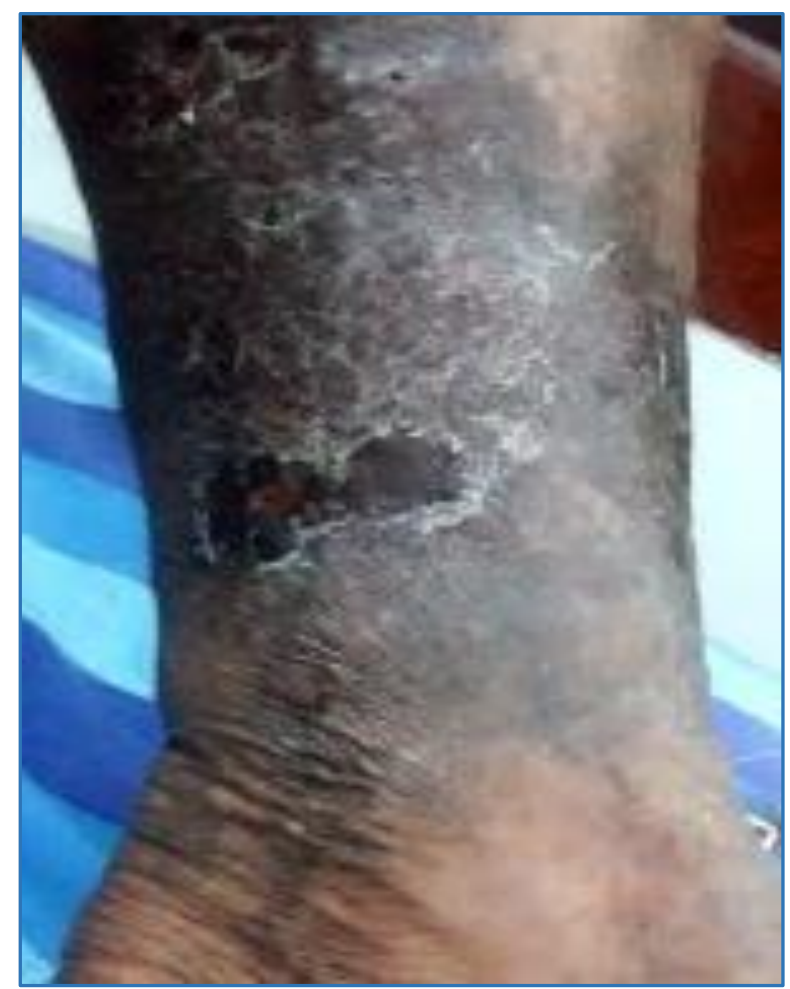

Fig. 1: Acroangiodermatitis: Ulcerated, lichenified and hyperpigmented plaque over the lateral malleolus of right leg 


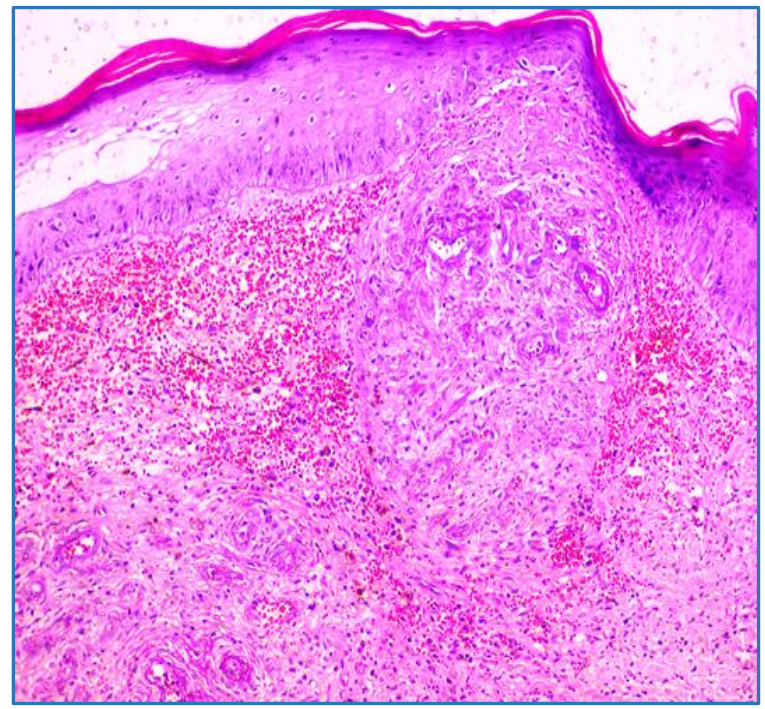

Fig. 2: Acroangiodermatitis: Lobular proliferation of capillaries in the dermis with extravasated erythrocytes and hemosiderin deposition (H\&E, 10x)

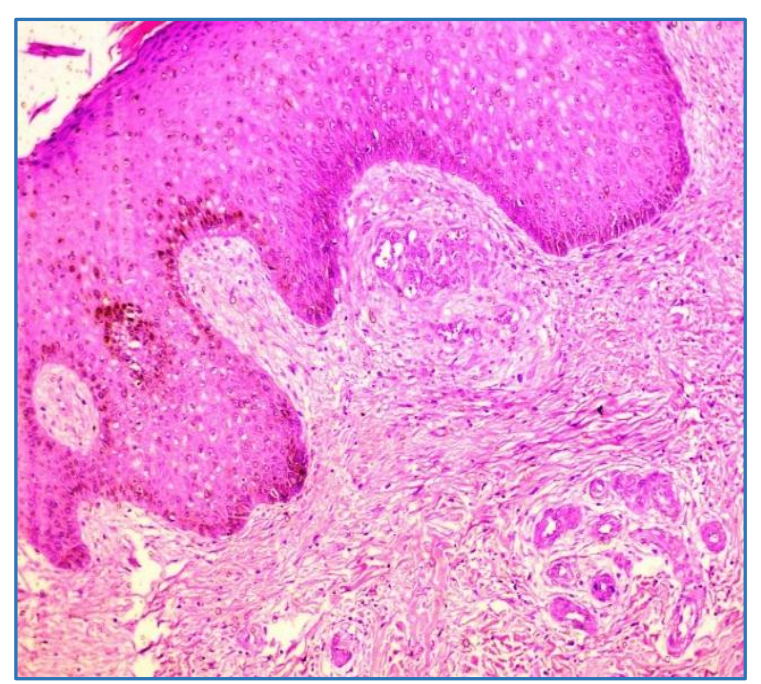

Fig. 3: Acroangiodermatitis: Proliferating capillaries in the dermis lined by plump endothelial cells without atypia (H\&E, 20x)

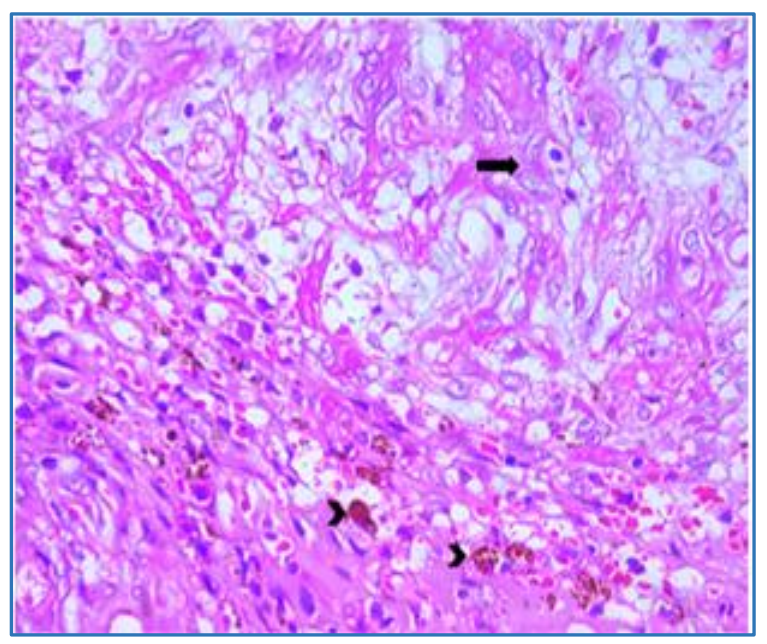

Fig. 4: Acroangiodermatitis: Plump endothelial cells lining proliferating capillaries [arrow] and siderophages [arrowheads] (H\&E, 40X)

\section{DISCUSSION}

Acroangiodermatitis is a rare vasoproliferative disorder of cutaneous blood vessels. ${ }^{2,5}$ It is a benign, exaggerated form of stasis dermatitis and begins as violaceous macules and patches. They develop into nodules or indurated plaques over time, usually bilaterally on the extensor surfaces of lower extremities. ${ }^{1,4}$ It may present in childhood or early adult life according to the underlying cause. ${ }^{2}$

It has various synonyms, such as acroangiodermatitis of Mali-Kuiper, gravitational purpura, stasis purpura, acral capillary angiomatosis and pseudo-Kaposi sarcoma. ${ }^{2}$ Mali et al. coined the term "Acroangiodermatitis" in 1965 and is currently the preferred term in literature.2,4 Variants of acroangiodermatitis include the Mali type associated with chronic venous insufficiency, the Stewart-Bluefarb type associated with arteriovenous malformations, gravity purpura in pregnancy and those associated with arteriovenous shunts in hemodialysis. ${ }^{2}$

Acroangiodermatitis is a proliferation of pre-existing vasculature seen in patients with increased venous pressure and stasis caused by venous insufficiency, congenital or acquired arteriovenous anomalies and lower limb paralysis or amputation stumps. ${ }^{1}$ However, cases with neither venous insufficiency or any underlying arteriovenous malformation have been reported as spontaneous acroangiodermatitis. 2,3

Histologically, there is expansion of the capillary bed in the dermis. The thick-walled capillaries are lined by CD34 positive, plump endothelial cells. The proliferating vessels form nodular aggregates in the dermis along with perivascular fibroblasts, extravasated RBCs and hemosiderin deposition. In patients with chronic venous insufficiency, prolonged increased venous pressure leads to proliferation and dilatation of veins in the superficial venous plexus as well as in papillary and reticular dermis. This along with red cell extravasation results in the characteristic skin lesions and discoloration. 6

The most important differential diagnosis for acroangiodermatitis is Kaposi sarcoma, which it resembles both clinically and histologically, particularly in the early stages of Kaposi sarcoma. On microscopy, acroangiodermatitis is characterized by marked benign proliferation in the papillary and reticular dermis of pre-existing blood vessels, which are round and regular. The vessels are lined by plump endothelial cells, which are Factor VIII-related antigen and CD34 positive. Kaposi sarcoma, on the other hand, is a malignant tumor characterized by neoplastic spindle cells forming irregular clefts, slit-like spaces and vascular channels, independent of pre-existing vessels and arranged as lobulated masses deep within the dermis. The lining endothelial and perivascular spindle cells are CD34 positive and Factor VIIIrelated antigen negative. Endothelial cells in Kaposi sarcoma show atypia unlike acroangiodermatitis, where there is minimal or no atypia. $1,2,6$

\section{CONCLUSION}

Acroangiodermatitis is a rare benign condition, seen to occur in association with various causes of vascular stasis, chronic venous insufficiency or spontaneously. It resembles the malignant Kaposi sarcoma clinically and histopathology is essential to make the distinction. 


\section{REFERENCES}

1. Mehta AA, Pereira RR, Nayak CS, et al. Acroangiodermatitis of mali: a rare vascular phenomenon. Indian J Dermatol Venereol Leprol 2010;76:553-6.

2. Coban I, Kokenek-Unal TD, Alper M. Spontaneous acroangiodermatitis. Indian J Dermatol 2015;60:268-71.

3. Hung NA, Strack M, Rij AV, et al. Spontaneous acroangiodermatitis in a young woman. Dermatology Online Journal 2004;10(2):8.
4. Singh SK, Manchanda K. Acroangiodermatitis (PseudoKaposi sarcoma). Indian Dermatol Online J 2014;5:323-5.

5. Samad A, Dodds S. Acroangiodermatitis: review of literature and report of a case associated with symmetrical foot ulcers. Eur J Vasc Endovasc Surg 2002;24:558-560. doi:10.1053/ejvs.2002.1772, available online at http://www.idealibrary.com.

6. Bulat V, Lugovic L, Situm M, et al. Acroangiodermatitis (Pseudo-Kaposi sarcoma) as part of chronic venous insufficiency. Acta Clin Croat 2007;46:273-277. 